\title{
Visualization and Assessment of Changes in Understanding Item Relational Structure of Japanese Language Particles in Japanese Language Learning Process -Application to Mongolian-Japanese Grammar Comparison
Technique
}

\author{
SIRIGONG $^{1}$, Katsuko T. NAKAHIRA ${ }^{2}$ and Takashi YUKAWA ${ }^{3}$ \\ ${ }^{1}$ Nagaoka University of Technology \\ Nagaoka, 940-2188/ Niigata, Japan \\ ${ }^{2}$ Nagaoka University of Technology \\ Nagaoka, 940-2188/ Niigata, Japan \\ ${ }^{3}$ Nagaoka University of Technology \\ Nagaoka, 940-2188/ Niigata, Japan
}

\begin{abstract}
In this paper, we propose a monitoring method of the status of learning Japanese case markers for Mongolian native speakers who live in Inner Mongolia Autonomous Region. The monitoring method consists of three steps -- introduce the ideal relationship structure suggested from case markers usage, assess learner's acquisition status for case markers usage, and compare them. To introduce the ideal relationship structure, we borrow an idea from graph structure. The case markers usage elements are regarded as graph node and the relations derived from case markers usage grammar books as graph link structures. Using them, we construct the relationship structural graph between case markers usage items. To assess learner's acquisition status, we conduct online examinations which include examination items for all case markers usage elements. Using the results of learner's correct/wrong answer patterns derived from the examination, we represent the learner's acquisition status as Item Related Structure (IRS). Comparing link structure between relationship structural graph and IRT results, we assess the difference of learner's case markers usage acquisition. Continuing the method, we follow-up the process of its acquisition from IRS graph restructure.

Keywords: A Japanese case particle, Inner Mongolian learner, Mongolian and Japanese grammar comparison, Item Related Structure.
\end{abstract}

\section{Introduction}

With the growth of ICT, e-learning has extended its function from just delivering stereotypical learning materials with inflexible learning courses to providing more adaptive materials and courses that fit learners' knowledge acquisition levels. The development of learning analytics (LA) [1] enables us to provide the learners with adaptive e-learning for optimizing the process of knowledge acquisition by using their learning activity logs. In adaptive learning, learning is carried out in the form of iterative e-learning, which is one the major advantages of e-learning. On each turn of an iterative e-learning session, a learner's activity is recorded as a log file and his/her knowledge level is accessed by a set of examinations, and the result of assessment is used to select the contents to be provided for the next turn of the session from the viewpoint of optimizing the entire learning session in terms of the degree of efficiency of knowledge acquisition rate.

Iterative learning is a classical style for mastering basic academic skills. However, it is monotonous and easily deprives the learner of motivation of continuing the learning. However, iterative e-learning makes possible to provide flexibility and adaptability for delivering materials to the learner in such a way to maintaining the motivation of learning.

This paper applies iterative e-learning to language learning; it demands the learner to memorize grammar, words, idioms, and so on, a lot of things, which is the necessities of acquiring language literacy, with a great deal of patience in continuing iterative learning. 
There are a lot of e-learning materials for language learning. In case of Japan, many e-learning materials for Japanese language is developed for effective support to international students in combination with policy to attract international students which Japanese government conducts $[2,3]$. Currently, the way to build e-learning materials for Japanese language is mirrored view-to-view teaching style. The teaching style in Japanese-language education is divided to Input type (mainly memorization and iteration), Output type (teacher's correction and advice), and Interactive type (interaction among learners) [4].

The Input type is particularly suitable for e-learning, in which grammar learning is tailored to usage of the language. Unlike memorization of words alone, the Input type requires both memorization and iteration for the purpose of correct usage of grammar. Different from memorization words and idioms, acquiring usage of grammar is difficult by simple iterative learning. The difficulty for acquiring usage of grammar is derived two reasons: learners' common reasons and personal-specific them. To reduce them, we propose a monitoring method of learners' language grammar usage acquisition status. The basic idea is three steps: introduce the ideal structure of acquisition process constructed by grammar elements, assess learners' knowledge acquisition status, and compare them.

For Japanese language acquisition, the most important grammar element is "particles". Especially, case markers are very important but difficult to acquire correct usage. Therefore, if the monitoring method is realized, it is useful applying to Japanese case markers in the view point of optimizing language learning method. Through e-learning and online assessment test for learners' knowledge conformation and its correct/wrong answer pattern and comparing ideal structure of acquisition process, the optimization will be able to realize.

In this paper, we propose a monitoring method of the status of Japanese case markers and its visualization. The targeted learners are Mongolian native speaker who are increasing to want to study in Japan. We adopt MongolianJapanese grammar comparative learning technique [5] that utilizes the visualization of the structure of Japanese language case particle usage by the Mongolian speaking learners. The experiment and the subsequent analysis was conducted by utilizing e-learning and on-line knowledge tests. Mongolian is an agglutinating language like Japanese with the same order of elements in a sentence, and case particles play central role in the both languages. For the Mongolian native speakers who want to learn Japanese, there is an opportunity for them to classify the particles in
Japanese language based on the rules in their mother tongue so that there is little obstacles in understanding the case particles exit in Japanese. Nevertheless, it is observed that mastering of the case particles are difficult and improper usage of " ni", " de" and "wo" are quite common $[6,7]$.

Mongolian-Japanese grammar comparative learning technique is applied to case particles. We created internet based teaching materials and used them in our experiment, which we analyzed with following steps. At first, in order to explain the many-to-many relationship shown in the Mongolian-Japanese particle correspondence chart, we designed a structure chart of Japanese cases articles for the Mongolian native speakers. Then we visualized how the learner understood and correctly used the Japanese case particles before and after utilizing the Mongolian-Japanese grammar comparative learning technique presented as an item relational structure graph. We then evaluated the gap from the structure of Japanese case particles. Based on the results from above analysis, the effectiveness of Mongolian-Japanese grammar comparative learning technique was assessed.

\section{Structure of Japanese case particles in the Mongolian - Japanese Case particle Correspondence Chart}

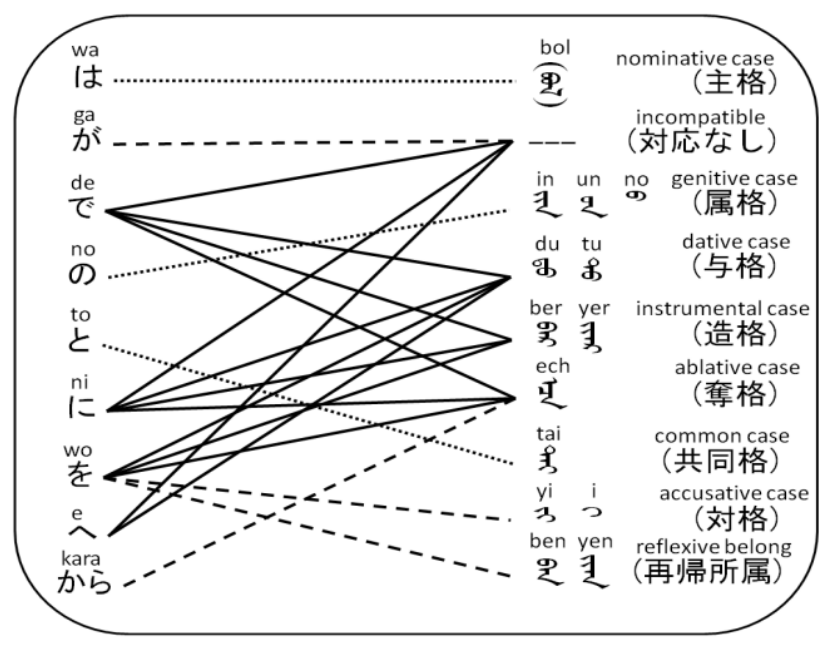

Fig.1 Mongolian-Japanese case particle correspondence chart (Revision based on [5])

This section comparing the Item relevance structure of Japanese case particles with those of Mongolian case particles, this section attempts to explain what kind of semantic variant relevance that Mongolian learners of Japanese have for the particles in the two languages will 
have a positive effect on making their acquisition of Japanese case particles smoother. The Mongolian language has case participles corresponding to those in Japanese.

Fig. 1 shows the correspondence between the case particles in Japanese and Mongolian. In general, there are one-toone relationships as well as many-to-many relationships between Japanese case particles and Mongolian ones. In our experiment, in order to facilitate the teaching activities, we organized the case particle knowledge into distinct concepts which consists of several items. We added order structures to each item from easy to difficult level to be taught step by step according to this order. In this study, based on our understanding of Mongolian case particles and the levels of difficulty in the usage of Mongolian case particles and Japanese case particles, we constructed a conceptual structure of Japanese case particles for Mongolian learners. The conceptual structure of Japanese case particles is shown graphically. Fig. 1 shows the correlation between the case particles in Japanese and Mongolian. As we can see in Fig.1, the conceptual structure of Japanese case particles can be described based on their correlation to Mongolian ones, on the one hand, and that of Mongolian case particles can also be described based on their correlation to Japanese ones. Because, for Mongolian native speakers, the latter is most likely to invoke the concepts they already possess, based on various Mongolian grammar books $[8,9,10]$, we, in our chart, reproduced the relationships between each usage as Japanese case particles for correlating Mongolian case particles.

Fig.2 represents the conceptual structure of Japanese case particles adopted in this paper. The conceptual structure here is presented as learners' mental representation of Japanese case particles that is available when they have full comprehension of the correspondence between case particles in Mongolian and Japanese by virtue of comparison between them. Note that in Fig.2 Japanese case particles are ordered according to the degree of difficulty in learning each of their semantic variants and the frequency of occurrence of corresponding Mongolian case particles in various texts. In particular, for example, Fig.2 (1) is made up as follows. According to the frequency of their occurrence in various texts, Mongolian case particles are arranged in this order: dative case $(\mathrm{Y})$, instrumental case (Z), ablative case (D) and nocorrespondence $(\mathrm{N})$. As for dative case, since $\mathrm{Y} 2$ and $\mathrm{Y} 3$ are two dative semantic variants of the same particle, they are described as having equivalent relevance. However, given the frequency of their occurrence in various texts, Y2 is more familiar to learners and therefore Y3 is more difficult for them to learn than Y2. Since it is the most basic one among the dative meanings, $\mathrm{Y} 1$ is easiest to learn. Learners who have learned $\mathrm{Y} 2$ and $\mathrm{Y} 3$, which are more
(1)

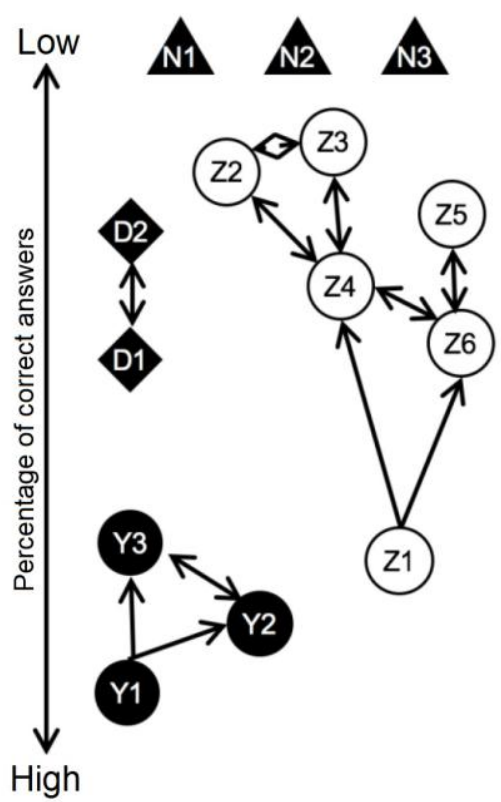

(2)

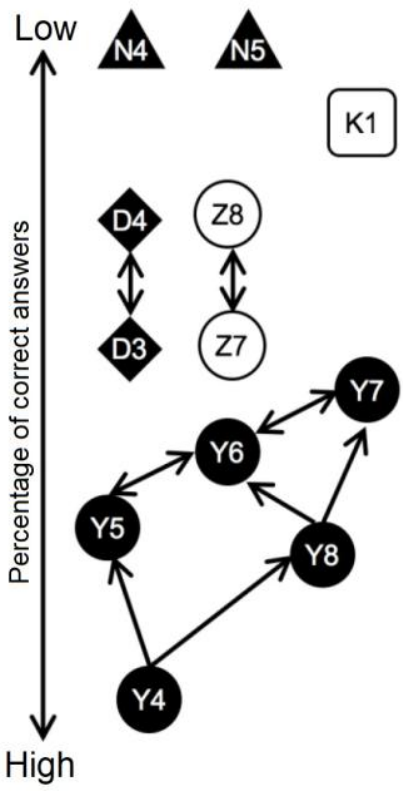

(3)

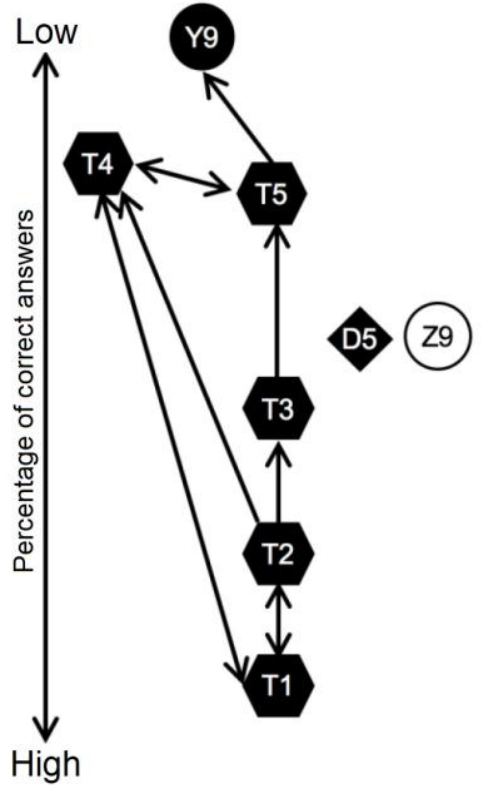

The creation of the structures in Fig. 2 was based on the Mongolian-Japanese case particles correspondence charts used in this study. The meaning of arrows, alphabets and numbers in the structure are explained below. Bidirectional arrows denote equivalence, unidirectional arrow denotes sequence, Y represents dative case, D represents ablative case, $\mathrm{Z}$ represents instrumental case, $\mathrm{K}$ represents comitative case, T represents accusative case. The numbers in the charts are: (1) is for "-de", (2) is for "-ni", (3) is for "-wo". 
difficult than Y1, must have learned Y1, too. As for Japanese, the particle "de", as the counterpart of a corresponding Mongolian particle, has three semantic variants to express dative. We have seen how Fig.2 (1) is made up, and the same formulation also applies to Fig.2 and Fig.3.

\section{Measurement of the understanding of case particle usage before and after utilizing the Mongolian-Japanese grammar comparative learning technique}

To measure the understanding of case particle usage, we conducted knowledge tests on November 13th, 2015 to learners who are already in first year to the fourth year Japanese courses at Inner Mongolia University. The purpose of the tests were to quantify their understanding of case particle usage before and after utilizing the Mongolian-Japanese grammar comparative technique. These students had been learning Japanese since they entered the university and the length of their study correlated to the year they were in at the university. The first step was that the students had a Japanese language Proficiency Test before learning the Mongolian-Japanese grammar comparative learning technique. The next step involved the students using web teaching material for case particle learning. The third step was that the students took the same level tests as before. In the last step, we conducted a comprehension test on Mongolian case particles.

The before and after learning tests, web based teaching materials for case particles, and the Mongolian case particle comprehension test were created by the following procedures.

The web based teaching materials used in this experiment were designed based on the Mongolian-Japanese grammar comparative learning technique [5]. The following items were designed as one set: Japanese case particle to be learned, explanation of case correlation between the two languages based on the Mongolian-Japanese particle correspondence chart, example sentences in Japanese and their Mongolian translation, and situation explanation chart. The number of sets of the teaching material were prepared based on the number of case particles to be learned. In addition, for those items that did not have corresponding relationships or that had multiple corresponding relationships, the teaching material sets primarily used explanation, example sentences, and the situation explanation chart.
The before and after tests were designed based on "Mongolian Japanese particle correspondence chart" for Japanese case particles. Each case in Mongolian language, dative case for example, was given as a question to all items corresponding to Japanese case particles. The answer format was a short sentence, and fill-in-the-blank multiple choice questions with four answer choices. Presentation of this test was web-based. The questions were designed at elementary level which is equivalent to the level of Japanese Language Proficiency Test N3, and the design was reviewed and confirmed by a Japanese lecturer. The total number of questions was 79. In the Mongolian language comprehension test, five questions were given for each case such as accusative case, instrumental case, dative case, ablative case and comitative case that are commonly found in sentences in Mongolian. The test questions were also confirmed to be well designed by a Mongolian language teacher. The format of the questions was also a short sentence and fill-in-the-blank multiple-choice with four answer choices.

The average score on the test before and after the learning was 57.0 and 76.4 respectively. The average score increased 18.5 points and the t-test result shows a significant difference at $1 \%$ level. Table 1 shows the result of pre and post learning tests for each student class.

Table1. Before and after learning test results for each class

\begin{tabular}{|c|r|r|r|r|}
\hline & \multicolumn{2}{|c|}{$\begin{array}{c}\text { Test } \\
\text { results }\end{array}$} & \multicolumn{2}{c|}{$\begin{array}{c}\text { Standard } \\
\text { deviation }\end{array}$} \\
\cline { 2 - 5 } & $\begin{array}{c}\text { Before } \\
\text { learning }\end{array}$ & $\begin{array}{c}\text { After } \\
\text { learning }\end{array}$ & $\sigma_{\text {Before }}$ & $\sigma_{\text {After }}$ \\
\hline $\begin{array}{c}\text { 1th year students } \\
\text { (9 people) }\end{array}$ & 30.3 & 57.0 & 5.3 & 1.3 \\
\hline $\begin{array}{c}\text { 2th year students } \\
\text { (5 people) }\end{array}$ & 58.7 & 74.0 & 14.1 & 11.6 \\
\hline $\begin{array}{c}\text { 3th year students } \\
\text { (9 people) }\end{array}$ & 63.9 & 82.8 & 5.0 & 6.1 \\
\hline $\begin{array}{c}\text { 4th year students } \\
\text { (7 people) }\end{array}$ & 83.3 & 93.5 & 4.6 & 2.5 \\
\hline
\end{tabular}

Overall, the result shows improvement, especially among the first year class that has demonstrated a significant improvement after the learning. Also, looking at the standard deviation, the variation of the test results from before and after the learning decreased ( $\sigma$ before: 5.3, $\sigma$ after: 1.3) among the first year students. The result of the ttest shows that there are significant differences between the second year student, who has the result of 5 percent level and the other students whose result was 1 percent level. The first and the second year students who have not much experience in learning can be expected to improve their grades by using any kind of learning method. However, we found that the Mongolian-Japanese grammar comparative learning technique is effective not only for the students at 
the early stage of Japanese learning, but also effective for the students at advanced stage in their Japanese learning. This can be seen from the improvement of grades of the third year and fourth year students who have already experienced case particle learning in the past.

\section{Analysis of the IRS of Japanese case particles based on Mongolian case particle usage}

In order to understand the usage of case particles correctly, the comprehension structure should be similar to the conceptual structure described in Section 2. By comparing the Item Relational Structure (IRS) graph with the conceptual structure graph, it is possible to analyze whether the learning material helps the students learn the case usage correctly. We analyzed the IRS from the result of the before and after learning test obtained in Section 3 and compared with the structure of Japanese case particles.

IRS analysis is a method of analyzing items to measure the kind of comprehension structure formed among the students for each items (questions) on the test by grouping these items. In other words, from the assumption of the order of comprehension for items such as "The learners who understand item 1 would surely understand item 2", we constructed the relationship structure between each items on the test[11]. In this paper, we observed how the students understood Japanese case particles by relating them to the usage of case particles in Mongolian language and by using the IRS analysis. By analyzing the details of case particles in Mongolian and the sequential relationship between their usages, it is possible to know much about the comprehension structure of Japanese case particles of the learners.

In conducting the IRS, Mongolian case particles and their usage are utilized for the usage items. As a precondition, the learners must correctly understand the usage of Mongolian case particles. With this assumption, we confirmed the results of the learners' comprehension test. The average score for the each item are, $100 \%$ for dative and comitative case, $95.5 \%$ for genitive case, $90.0 \%$ for accusative case, $88.0 \%$ for instrumental case and $85.5 \%$ for ablative case. Therefore, we concluded that learners could use Mongolian case particles with correct usage and IRS analysis can be performed.

Fig. 3 includes the IRS graphs for the tests before and after the learning. The left side is the IRS graph before the learning and the right side is the IRS graph after the learning. The vertical axis shows the correct answer rate, the upper part shows a low rate of correct answers (high
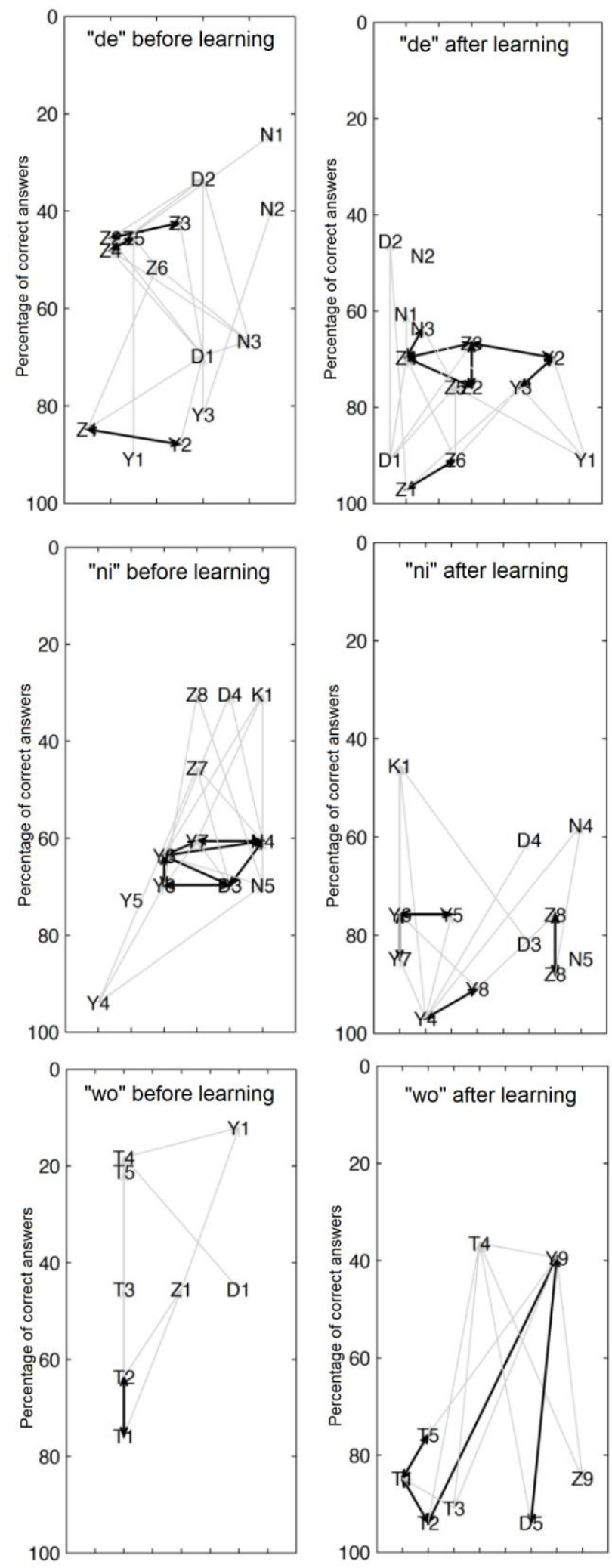

Fig. 3 IRS graph of the tests before and after learning case particles 
difficulty items), and the lower part shows the high rate of correct answers (low difficulty items). The correct answer rate in the IRS graph for all items of "de", "ni" and "wo" shows that the axis of the correct answer rate for the after learning test in the IRS graph has moved lower than that in the IRS graph before learning and it is clear that the students' grades has risen.

In order to compare the IRS graph before and after learning in Fig. 3 and the structure of Japanese case particles, a comparison is made for each case item to document the transitional changes between the two tests on their sequential relationship.

Table 2. Matching between the IRS graph from before and after learning case particles and the structure of Japanese case particles

\begin{tabular}{|c|c|c|c|c|}
\hline \multicolumn{2}{|c|}{$\begin{array}{l}\text { Comparison with the } \\
\text { conceptual structure of } \\
\text { Japanese case particles }\end{array}$} & \multirow[t]{2}{*}{ ni } & \multirow[t]{2}{*}{ de } & \multirow[t]{2}{*}{ wo } \\
\hline $\begin{array}{l}\text { Test of before } \\
\text { learning }\end{array}$ & $\begin{array}{l}\text { Test of after } \\
\text { learning }\end{array}$ & & & \\
\hline \multirow{3}{*}{$\begin{array}{l}\text { Complete } \\
\text { mismatching }\end{array}$} & $\begin{array}{l}\text { Complete } \\
\text { matching }\end{array}$ & $38.9 \%$ & $41.2 \%$ & $22.2 \%$ \\
\hline & $\begin{array}{l}\text { Partial } \\
\text { matching }\end{array}$ & $5.6 \%$ & $5.9 \%$ & - \\
\hline & $\begin{array}{c}\text { Complete } \\
\text { mismatching }\end{array}$ & $22.2 \%$ & - & $22.2 \%$ \\
\hline \multirow{3}{*}{$\begin{array}{c}\text { Partial } \\
\text { matching }\end{array}$} & $\begin{array}{l}\text { Complete } \\
\text { matching }\end{array}$ & $5.6 \%$ & - & - \\
\hline & $\begin{array}{l}\text { Partial } \\
\text { matching }\end{array}$ & $\begin{array}{ll}- & -1 \\
\end{array}$ & $17.7 \%$ & - \\
\hline & $\begin{array}{l}\text { Complete } \\
\text { mismatching }\end{array}$ & $11.1 \%$ & - & - \\
\hline \multirow{3}{*}{$\begin{array}{l}\text { Complete } \\
\text { matching }\end{array}$} & $\begin{array}{l}\text { Complete } \\
\text { matching }\end{array}$ & $5.6 \%$ & $29.4 \%$ & $11.1 \%$ \\
\hline & $\begin{array}{l}\text { Partial } \\
\text { matching }\end{array}$ & - & - & $11.1 \%$ \\
\hline & $\begin{array}{l}\text { Complete } \\
\text { mismatching }\end{array}$ & $11.2 \%$ & $5.9 \%$ & $33.3 \%$ \\
\hline
\end{tabular}

Table 3. Transition of the structure between IRS graphs before and after learning for the items except the same case

\begin{tabular}{|c|c|c|c|c|}
\hline \multicolumn{2}{|c|}{} & de & ni & wo \\
\hline Dative case-other cases & $\begin{array}{c}\text { Before } \\
\text { After }\end{array}$ & $\begin{array}{c}14 \\
7\end{array}$ & $\begin{array}{c}15 \\
5\end{array}$ & N/A \\
\hline $\begin{array}{c}\text { Instrumental case-other } \\
\text { cases }\end{array}$ & $\begin{array}{c}\text { Before } \\
\text { After }\end{array}$ & $\begin{array}{c}19 \\
12\end{array}$ & $\begin{array}{c}6 \\
3\end{array}$ & N/A \\
\hline $\begin{array}{c}\text { Ablative case-other } \\
\text { cases }\end{array}$ & $\begin{array}{c}\text { Before } \\
\text { After }\end{array}$ & $\begin{array}{c}13 \\
7\end{array}$ & $\begin{array}{c}10 \\
1\end{array}$ & 2 \\
\hline $\begin{array}{c}\text { Accusative case-other } \\
\text { cases }\end{array}$ & $\begin{array}{c}\text { Before } \\
\text { After }\end{array}$ & N/A & N/A & $\begin{array}{c}5 \\
7\end{array}$ \\
\hline $\begin{array}{c}\text { Common case-other } \\
\text { cases }\end{array}$ & $\begin{array}{c}\text { Before } \\
\text { After }\end{array}$ & N/A & 8 & N/A \\
\hline
\end{tabular}

Based on the results in Fig. 3, Table 2 shows the matching of IRS graphs from before and after the learning and the structure of Japanese case particles constructed in this study the match is for the usage items of each case particle such as "de", "ni" and "wo". We then categorized the degree of matches into "complete mismatching", "partial matching" and "complete matching".

Complete matching refers to a situation when the matching of sequential relationship between items with the structure of Japanese case particle is $100 \%$. Complete mismatching refers to a situation where the matching of sequential relationship between items with the conceptual structure of case particle is $0 \%$. The situation other than "complete matching" and "complete mismatching" is "partial matching".

Next, Table 3 shows the transition of the structural relevance with items other than the same case particle. It can be seen in Table 2 that there is an improvement in comprehension structure of "ni" and "de". We can see from Table 3 that, as for cases other than "accusative case" including dative case, instrumental case and ablative case, the relationship with another case decreased greatly, and it is seen that the correct answer rate increased due to the improvement of the conceptual structure of Japanese case particles by "Mongolian-Japanese grammar comparative learning technique" learning materials.

\section{Conclusions}

In this paper, we visualized the change of the conceptual structure of Japanese case particles before and after learning the materials based on "Mongolian-Japanese particle correspondence chart". This chart applies Mongolian-Japanese grammar comparative learning technique to case particles for which the IRS graph was utilized. We then proposed a method of analysis, created the learning contents, conducted the learning activities, administered the on-line test, and analyzed the outcome. We compared the structure of Japanese case particles designed by the authors of the teaching material and also compared the results of the two tests conducted before and after learning with the conceptual structure graph. As a result, the rate of correct answers rose to 18.5 percent on the test administered after learning the materials of "Mongolian-Japanese grammar comparative learning technique" compared to the result from the test administered before learning the technique. Also, the t-test result showed a significant difference of 1 percent. Moreover, we can see from the result of the IRS analysis that the values indicating "Complete mismatching Complete matching" gathered before and after the presentation of the learning material were high in "de" and "ni", which were $38.9 \%$ and $41.2 \%$ respectively. This suggests that the efficiency and the effectiveness of learning the structure of Japanese case particle was 
improved by utilizing the learning materials of the "Mongolian-Japanese grammar comparative technique". In "wo", on the other hand, it was found that fewer items were improved compared with "de" and "ni".

The method proposed in this paper visualizes changes of the structure of understanding of case particles before using teaching materials of the structure of Japanese case particles. It also visualizes the changes of structure of understanding of case particles before and after learning by the Mongolian-Japanese grammar comparative learning technique. However, this method is not limited to case particle. It can also be applied to other grammatical elements. We believe that, in the future, this method can be used to analyze all word classes in grammar of different languages including case particles for the Mongolian students. In addition, by comparing the structure of Japanese case particles with the Japanese case particle comprehension structure and the individual result of the test conducted before learning the technique, it is possible to design effective e-learning teaching materials that are suitable to the group. Moreover, by comparing the case particle comprehension structure and the individual result of the test conducted before learning, it is possible to provide effective e-learning teaching materials that are suitable for each learner's need for mastering the Japanese particle case comprehension structure. In the future, we will design and implement a system to conduct a large scale test before and after learning and to analyze the results by implementing a Japanese case particle test (before/after learning). The test will be designed as an etest to enhance the quality and the quantity of the questions. With that, it will be possible to accurately capture the structure of Japanese case particles in the minds of the Mongolian students in Inner Mongolia. Using the results, we believe it will be possible to further improve the teaching materials used in learning "Mongolian-Japanese grammar comparative learning technique". Furthermore, the application of this method will make it possible for speakers of other languages than Mongolian to design a similar learning materials and technique to suite their own understanding of the structure of Japanese case particles.

\section{Acknowledgments}

In this study, Professor Kenjiro Nagano at International Collaboration Center, Nagaoka University of Technology collaborated with us to create the questions on Japanese particles, and professor Menggen at Foreign Language Academy, Inner Mongolia University assisted us during the evaluation tests. We greatly appreciate the above two professors for their guidance and effort.

\section{References}

[1] "1st International Conference on Learning Analytics and Knowledge” , 2011, https://tekri.athabascau.ca/analytics/ (accessed 2017.09.29)

[2] U. Ryuichi, M. Terumi and I. Ryusuke, "Development of on-line technology Japanese language teaching materials for foreign students" , Japan Society for Educational Technology, Vol.27(suppl), 2004, pp. 157-160.

[3] H. Ikuko, K. Junko, H. Hironori and H. Shigeru, "ICTbased Japanese Learning Materials for International Students before Coming to Japan -Verification by the trial deliveries" , Computer \& Education, Vol.38, 2015, pp.74-79.

[4] Sh. Daishi, "Construction of the Integrated Blended Learning Model Specializing in Class for Input, and Development of Advanced Grammar Contents of E-learning Course in Japanese as a Second Language", Japanese Language Education Methods, Vol.20 (1), 2013, pp.12-13.

[5] Sirigong, N. Katsuko, F. Yoshimi and Y. Takashi, "Japanese Case Markers Learning Method for the Mongolian Learners - A Proposal for Grammar Comparison Type Learning Method -", Computer \& Education, Vol.41, 2016, pp.40-45.

[6] I. Mamoru and K. Yoshiko, "Problems on Acquisition of Japanese Case Markers "Wo-Ni-De" for Advanced Learners of JSL-A Latitudinal Study Using Particle Quiz", The Japan Foundation Japanese Language Institute, Vol.7, 1997, pp. 17-34.

[7] M. Yumiko and S. Shunichi, "The longitudinal case study on learning Japanese as a second language", Japanese-Language Education Overseas, Vol.2, 1992, pp.129-156.

[8] Erdenbilig, Uyanga, "Comparative of Case Markers relationship between Japanese and Mongolian”, Shinshu University Japanese Language Education, Vol.19, 2009, pp.1-11.

[9] Khuhbaatar, "Mongolian basic grammar", Interbooks, Inc., 1997.

[10]Cinggeltei, “A Grammar of Modern Mongolian”, Inner Mongolian People's Publishing house, 1999.

[11]T. Makoto, "Construction method and usage of IRS test structure graph", Japan Society for Educational Technology, Vol.5, 1980, pp.93-103.

SIRIGONG is a graduated student at Nagaoka University of Technology. Her major is educational technology.

Katsuko NAKAHIRA is an Assistant Professor at Nagaoka University of Technology. Her major is educational technology with ICT.

Takashi YUKAWA is a Professor at Nagaoka University of Technology, Ph.D. His research fields are intelligent informatics, Web informatics, and service informatics. 